\title{
INSPIRING ENGLISH TEACHERS: INDONESIA TERTIARY EFL STUDENTS' VOICE
}

\author{
Mobit $^{1}$, Fathuloh ${ }^{2}$, Kriswanda Krishnapatria ${ }^{3}$ \\ Program Studi Pendidikan Bahasa Inggris \\ Universitas Singaperbangsa Karawang \\ HS Ronggo Waluyo St. Karawang Indonesia
}

\begin{abstract}
This study aims to scrutinize tertiary students' voices against the teacher/ lecturer who inspires them. This study elaborates on two classes of English Language Study Program as the respondents. The data use a questionnaire containing several questions that elaborated the teachers' characteristics that can generate inspiration to the students. This study was designed by using the survey. Based on the data obtained it can be concluded that the teachers/ lecturers who inspire (tertiary) students are those who have the unambiguous characteristics of English teachers both characteristics and competencies. They are capable to develop concepts/ provide material that encouraged students easily comprehends the material, to color the process of learning in class with humorous atmosphere, and to make students laugh and refresh and to give suggestions as well.
\end{abstract}

Keywords: inspiration, inspiring teachers, inspiring teaching, motivational learners

\section{INTRODUCTION}

Recent studies that focus on inspiring teacher issues have not been able to confirm much of the inspiring teacher. Whereas the finding of the inspiring teacher would be beneficial for new teachers, even the senior teachers to reconstruct the teaching strategies. As a result of the lack of study, the guiding points of teaching strategies improvement developed slowly. The studies that currently conducted related to the inspiring teacher and inspiring teaching were a comparative study inspiring teacher of two countries' students, Indonesia and China (Lamb \& Wedell, 2013), the identification of inspiring teaching (Williams, Nixon, Hennessy, Mahon, \& Adams, 2016) and the role of learning space on teaching process (Campbell, 2019).

Inspiring teachings would not emerge without the creation of inspiring teachers; consequently, the teachers have significant roles in the teaching process. They have the ultimate role to build student sustainability (Jensen, Adams, \& Strickland, 2014). The inspiring teachers also caused by the design of space of learning such school and campus where the learning process performed (Campbell, 2019). The roles of the teachers are as inspirator, who always move 
and remind their student everlastingly. Therefore, the teacher and the student have a strong strategic relationship in the teaching and learning process and vise versa. Therefore, the teachers' role and spirit in the teaching (passionate) affect the students learning achievement (Tuğrul Mart, 2013), since they are interconnected each other to gain the learning target.

Teachers have a significant role in learning sustainability in the classroom. Moreover, the teachers are as if the representative of parents at school as well as inspirator. The ultimate goal of the teachers' role is how to educate students to have a good attitude and behavior. Whatever is stated by the teacher will often motivate the students, so that the students committed to obeying the teachers' suggestion. Psychologically the relationship between the teacher and the students within the learning process are positive.

\section{INSPIRING TEACHING AND INSPIRING TEACHERS}

Inspirational teaching is "going beyond teaching excellence through having a transformational, sustained, positive impact on students" (Lubicz-Nawrocka \& Bunting, 2019). With the teaching conducted by the teacher, students can create positive change in themselves. The teaching that can influence the student means those that can change the students have new sight, attitude, behavior, and paradigm. Therefore, the teachers' roles are not only as the knowledge transferer but should also create a foregrounding impact on the students. Classroom teachers could build students' potency within the learning process in the classroom. The potency which potentially developed is dignity, energy, self-management, community, and awareness (Harmin, 2006). In addition, inspirational teachers should be able to either encourage learner or inspires to encourage or bring significant change to the learner. Moreover, learning which inspires students is which that implements approaches, that focus on students' natural needs (Harmin, 2006). Obviously, the inspiring teacher needs three main components "which are all interrelated, those being; the actual teaching and learning experience; the design of the curriculum and the teacher/student relationship" (Williams et al., 2016)

Inspiring teachers are not only those who teach students at universities but also those who taught when they still studied in kindergarten, elementary, secondary or high school. All of education level could be the area of inspiration because the teachers should capable to create distinctive things (Harmin, 2006). They should take into account three factors: the teacher can focus on the highest students' demands, the teachers do not bring the potential of students in general, and the teacher's target is to focus on the five potential students that the teacher can encourage student success, such as dignity, energy, self-management, community, and awareness. By focusing on the learning approach on the five potential students, the teacher would obtain optimal results in teaching students.

Teachers are not only the inspiration maker in the inspiring teaching notion, but the learners' participation in creating inspirational teaching and learning is very pivotal. The teachers may not be able to create inspiring teaching or learning if the learners do not collaborate and maintain good relationships in initiating learning conditions that inspire the class. Jensen (2014) claimed, 
"Inspirational teaching involves a collaborative ethos and a partnership approach where students and teachers' roles and responsibilities are mutually constitutive in developing inspired learners". So that, inspirational teaching requires a collaborative ethos and collaborative approach that involves the roles and responsibilities of teachers and learners who are mutually beneficial for the development of inspired learners.

A teacher should take account for some supporting aspects to be an inspiring teacher. The teachers can teach the class when the school facilitate a good space of learning (Campbell, 2019). In addition, West (2010) argued that to be a teacher who inspires students (learners), the teacher must pay attention to such aspects in his teaching, for instance, the using body language properly, having good classroom management, teaching with fun and good language instruction. Since the significance of body language, West suggested that the teachers would not be inspiring ones without using good body languages. The use of good body languages may help the teachers produce spoken language properly and control the events in the classroom. In this case, the teacher must pay attention to the use of body language, facial appearance, understand six basic emotions (wonder, anxiety, sadness, disgust, anger, and happiness), posture, eye movements, hands, sounds, and giving instructions. By maximizing the potential for using the good and proper body languages, the teachers are expected to give positive impressions in their teaching.

Inspiring teaching also requires several other important aspects such as teaching enthusiasm, keeping a positive relationship with students, having high motivation and commitment and having high trust (Sammons et al., 2014). Those four aspects are conclusions from the opinions of the research respondents. Respondents in the study mentioned several characteristics, namely; possess and transmit enthusiasm, foster positive relationships with students, be flexible and adapt to practicality, make learning purposeful and relevant to students, offer good security and climate in the classroom, establish clean and positive classroom management, reflect implementation and develop collaboratively and creating innovation in the classroom.

\section{INSPIRING ENGLISH TEACHING}

Several studies focused on how teachers inspire their students. Therefore, by following the learning with the teacher, students are able to develop their potential, especially with regard to English language skills. No terminologies that have inspired (Jackson, 2010) in detail, especially in the context of learning English. More discussion on teaching in general inspiring teaching is more emphasized on how the teacher is always remembered by students, teachers who always appear different in teaching, or transformational teaching (Jackson; 2010, in Jensen). So that the understanding of the two is complimentary.

Motivating teaching is a teaching process that is able to change learners' attitudes and thoughts to have positive developments. Motivating teaching is identical with good teaching. If the teachers have good competency in teaching means they have good teaching (Bradley, Kirby, \& Madriaga, 2015). Moreover, Ramsden, Margetson, Martin, and Clarke (1995), Trigwell (2001) in Bradly at all 
(2015) identified the characteristics of good teaching. Practically, a good teacher should present the enthusiasm for subject and desire to share with students, modifying teaching to suit the students, subject matter and environment, encourage learning for understanding and concern about the development of students' critical thinking, ability to transform and extend knowledge, show respect for their students, interest in professional and personal growth with sustained high expectations. (Bradley et al., 2015)

Presenting such teaching criteria is not a simple effort. Teachers need the teaching culture and paradigm. Changing the attitudes and positive thinking will encourage the presence of a learning culture that will create such features. Moreover, sometimes the inspiration will provide a duplication of enthusiasm like the teacher, both the way and the ideals. The succeeding key of the language learner step as either the first language (EFL: English as a foreign language) or the second language (ESL / English as the second language) is enthusiasm, persistence, and commitment (Dornyei, 2001). Learners development can be measured by value; either cognitive, psychomotor or effective.

One learner does not necessarily have the same thrust as the others. Learning administrated in the classroom is able to provide reinforcement of good motivation to students. The process of strengthening the motivation of the second language learners (B2) is influenced by several things, including the level of language, the level of learners and the level of learning situations (Dornyei, 2001).

The level of the learners and the learning situation take apart in the quality of teaching. Culture, community, intellectual and pragmatic values, and benefits can influence the level of language (Dornyei, 2001). For the level of students, the individual characteristics of the learners themselves influence the students. Learners, who have seriousness in learning, are motivated than those who lack enthusiasm. The third level which also has a thrust is not inferior to both is a learning situation. The aspects that are dominant at this level are the course, teacher and group components. The components of the course include a syllabus, material, teaching methods and assignments given. While the teacher component includes personalities, behavior and teaching style/practice. Furthermore, the group component is the characteristic of the group where the learner carries out learning.

In conclusion, Jensen stated that inspirational teaching encompasses a number of things, namely that the teacher has knowledge and passion in the field he is engaged in, understanding his learning and knowledge, his learning environment is challenging and constructive and students are played as individuals, partners or colleagues (Jensen, 2014). Teaching English has different characteristics from other disciplines. These characteristics are because language not only focuses theory but also how to practice the theory in everyday life. Especially in the context of English as a foreign language (English as Foreign Language / EFL), where English is not used in general. This is a challenge for the teacher. Therefore the characteristics of inspiring teaching can be achieved by adopting a strategy or approach of five potential students (Harmin, 2006) and approaches (Sammons, Kington, Lindorff-Vijayendran, Ortega, \& Riggall, n.d.) 


\section{METHODOLOGY}

This study aims to investigate the factors of the inspiring teachers have been giving them inspiration to learning English determined by the tertiary university English students. The study utilizes the data were drawn through questionnaires, which were distributed in the two classes of the fourth semester of English training department in a university in Indonesia. The teachers who are considered as inspiring teachers for this research refer to all English language teachers who have taught the respondents since they studied at the elementary school level until the university level. Moreover, the inspiring teachers in this study are specifically those who have taught English at school (formal), tutoring or courses, and lecturers. This study uses a quantitative descriptive approach by relying on the survey method.

\section{RESEARCH RESULTS AND DISCUSSION \\ Teaching characteristics that inspire students to learn English.}

Teachers' personal characteristics and knowledge could influence teaching styles. For instance, the teachers whose humorous natural sense would apply the characteristics of humorous teaching as well. Conversely, the teachers who have no sense of humor would also have a serious teaching style. Therefore, teachers have to build their personal characteristic in order to have their teaching more attention-grabbing.

Chart 01 describes the teacher who inspires the students. In answering the research questions about teaching methods which inspire students, 40 respondents $(18 \%)$ chose the teachers who were able to explain the lesson well. Additionally, 38 (16\%) respondents were interested in a sense of humor in teaching. Then $27(15 \%)$ respondents chose teachers who were able to make the learning space interesting. Likewise, $23(13 \%)$ respondents chose teachers

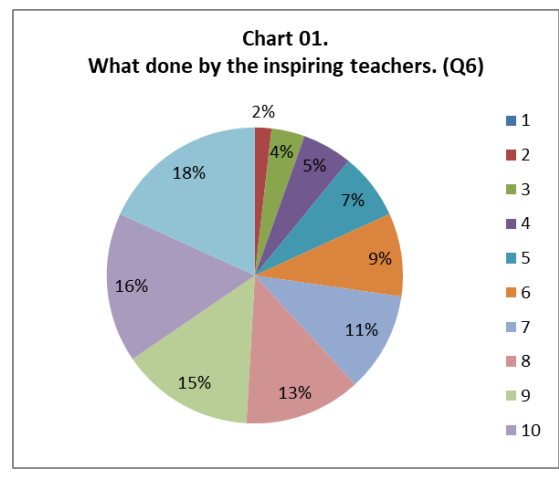
who gave suggestions related to learning. The four choices become the answers about kinds of teachers who are able to inspire students are those who are able to facilitate students in understanding the material or able to explain the material well, the third is having a sense of humor in teaching, teachers who are able to create interesting learning and teachers who give students input related to learning material.

The teachers have two aspects of quality, namely personal and professional quality. Personal quality is related to values and integrity that are inherent in the teachers when they are carrying out their duties or when not.

Chart 02 shows the choices of respondents in the learning process they have got. Thirty-six respondents $(33 \%)$ were more

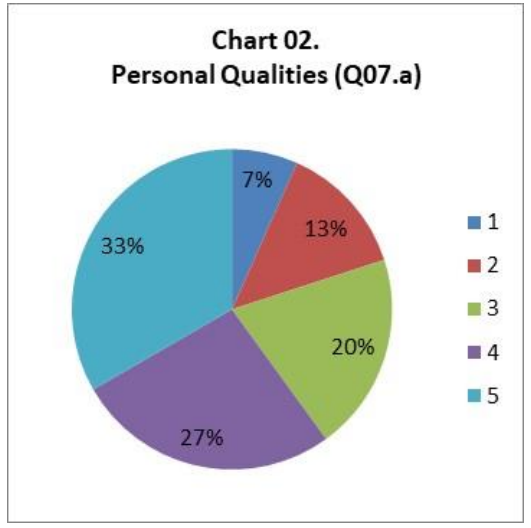


inspired by their teachers who had a good level of intelligence. While $23(27 \%)$ respondents felt more inspired by teachers who had good patience. Moreover, 22 respondents felt that the dedication of their teacher's good work had inspired him.

Professionalism is a very central aspect of the learning process. Chart 03 describes the percentage of respondents given the choice associated with the profession as an English teacher, 40 respondents $(25 \%)$ consider it important that the teachers who are knowledgeable and have good English language skills become a source of inspiration. Furthermore, 27 (23\%) respondents chose teachers who were able to understand the

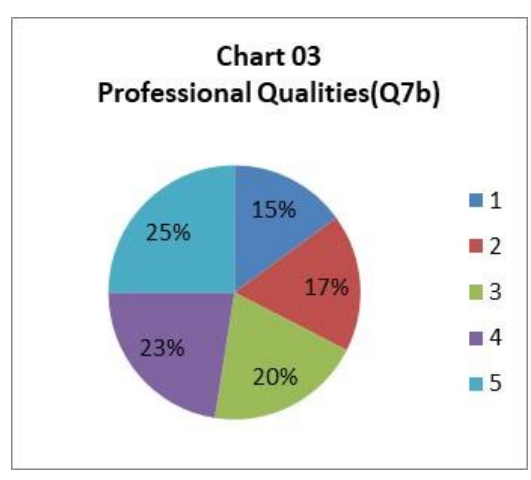
conditions of their students' needs. While $22(20 \%)$ respondents felt more inspired by the teacher who gave good treatment to students. Teachers whose good cultures are inspired by only $4(15 \%)$ respondents. Then, 19 (17\%) respondents chose the teachers who showed passion for English.

The relationship between the teacher and the student also plays a central role in the learning process or after the learning period. The teachers who have good relationships with students would have influence better on these students both inside and outside the classroom. In other word, a good relationship between teacher and student either class or outside the classroom becomes very significant for the sustainability of student spirit. When the respondents determined the type of relationship is the teaching inspiration, Chart 04 indicates 59 $(33 \%)$ of them defined the relationship between the teacher and the whole class. This means that the teachers who have good relationships with everyone have also inspired the students. While the slightest respondents indicated if the teachers have a very personal relationship with students, namely $24(17 \%)$ respondents.

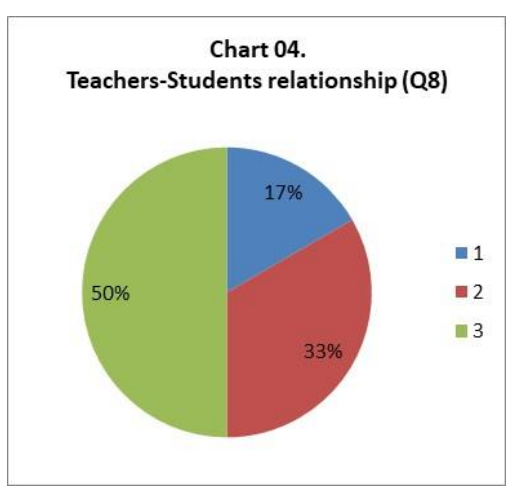

\section{Impact of teacher inspiration on the process of learning English in students.}

Inspirational teaching would have a positive impact on learners. The very basic change in the education process is the inspiration of students in several aspects. Chart 05 shows the highest percentage aspects influenced by the teaching are the students who like English (52/18\%). In addition, $43(16 \%)$ respondents were able to enjoy learning English better, and $26(15 \%)$ respondents felt that English was easier to learn than before. In

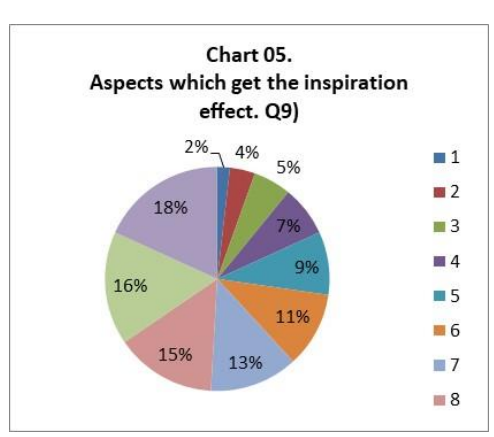
addition, $16(11 \%)$ respondents were increasingly aware that mastery of English was very important for their lives in the future.

Independence of learning is not a priority for the respondents. Only 4 (2\%) respondents who agreed that the learning process was more autonomous than 
before. $4(2 \%)$ respondents thought that their aspirations have altered. Inspiration interpretation can be determined by the age of the students. The consideration of assessment was based on the experience when studying with the teachers. The more experienced students are, the more complex their standards of inspiration would be. In other words, the more teachers who have taught students, they would be more matured to determine their inspirational standards.

Chart 06 explains the age when the respondents were taught by the teachers considered to provide inspiration related to English learning. The level of education that most teachers inspired the respondent was when in high school (27: $41 \%$ respondents). Whereas 24 (36\%) respondents got inspired when they studied at the university. It means that the senior high school teachers were found more inspiring than those in the university. Then, 9\% Elementary

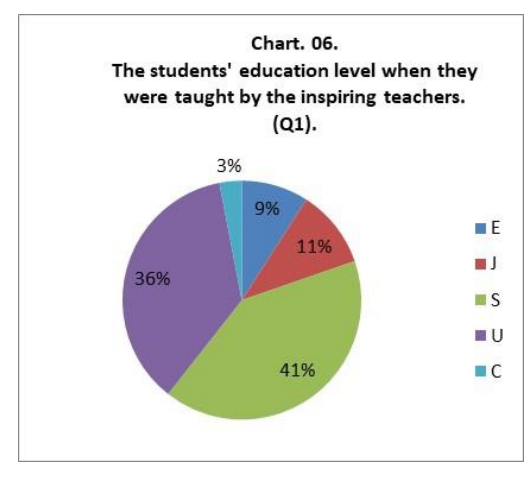
School, Junior High School (11\%), while the rest when respondents attend study in non-formal institutions (courses).

\section{DISCUSSION}

\section{Teaching characteristics which are able to inspire students to learn English.}

From the exposed data, it is identified that the respondents' choice of teaching which provides inspiration is the teachers whose skills to explain the material well, high sense of humor and competence to make the class more gorgeous. The respondents' answers confirmed the previous findings that teachers whose good teaching skills inspire students (M. Lamb \& Wedell, 2013). It is because, with easy-to-understand explanations, the students can hurriedly understand the material well. Conversely, if the teachers explain students the material in a convoluted manner, students would be unable to digest the language of explanation. Therefore, with the technique of explaining the material well and clearly, the students would be able to internalize the knowledge achieved well.

The inspiring teachers are those who are able to present humor in their teaching process (Elyildirim \& Ashton, 2006). The function of humor in the context of teaching is to provide psychoanalysis to students because the students would be able to eliminate boredom in the classroom. Teachers who can build a sense of humor naturally make the class fresher and more alive. This would strengthen the third choice, namely the attractive class atmosphere. These findings also reinforced previous research about the role of sense of humor in learning.

An interesting classroom atmosphere is the building between the role of teachers and students. Cooperation between the teachers and the students becomes very central points in classroom management. The teacher always needs to involve students in the learning process. If students are always involved in the learning process, it means that the activity of students in the class would also be built. Therefore, collaborative students' activity will generate student-centered learning. This also confirmed Harmin's opinion in focusing on students in the learning process (Harmin, 2006). 
Personally, the teachers who inspire students are those who have characteristic such as intelligent, patient and dedicated (Iftanti, 2015). Good intelligence is also shown by the teacher's language skills. Students can make teacher as a learning model both in terms of intelligence and language skills. Teachers whose good levels of intelligence would always be smart in teaching.

Professionally, the teachers who inspire students are those who also have good English knowledge and skills, the teachers who are able to understand students and have an ethical approach to students well. Teachers who inspire are also open to accepting criticism based on suggestions for improving their professionalism (Jensen et al., 2014). So, if the teacher is able to build himself with these characters (Iftanti, 2015), students would be inspired and have a positive influence on students and the teaching profession.

\section{Impact of inspiration on students' English learning process.}

Based on the description of the data, the respondents felt the impact of the teachers who inspired when teaching in the classroom. As explained in the characteristics of the teacher, the biggest influence felt by the respondents was that they assumed that English became more thought-provoking than when the respondents had not found inspired teachers. Fifty-two respondents thought that the teachers had helped them in making English more attractive (Sammons, Kington, Lindorff-Vijayendran, \& Ortega, 2014). This change is important because student interest in English would skyrocket if you get an inspiring teacher.

The choice of study program decision that has been chosen is not an unplanned decision. The decision on the selection of respondent study programs departs from considerations that would support the learning process. The decision was the impact of inspiring experience on his decisions regarding English (Jensen et al., 2014). However, only a few respondents thought that their inspirational teachers have not helped them become autonomous learners. In summary, the collaboration between the teachers and the students can build synergy and collaboration. Either the teachers or the students play their roles in the learning process. This is in line with the results of previous studies (Jensen et al., 2014).

\section{CONCLUSIONS}

The findings and discussion can be summarized as follows: characteristics of inspirational English teachings would have an impact on students' attitudes towards English. The teachers whose good teaching characteristics would also enable students to change for the better. Inspirational teaching characters are not gifts, but the teaching characteristics can be learned by the teachers' candidates and the teachers. The main and most compulsory thing is how English teachers can build concepts to afford material explanations that are easily understood by the students. Secondly, the teachers must try to color the learning process in the classroom with mild humor that makes students laugh and fresh. Thirdly, teachers do not hesitate to give suggestions that focus on related learning.

The respondents have sides that can be influenced by the inspiring things. If the teachers are able to find that side, the students can change according to the direction. From the discussion, it can be seen that students feel that after learning 
with an inspiring English teacher, students are able to find many things. The things that are felt by students are that they have a different view of English, enjoy language learning, now learning English is easier.

\section{REFERENCES}

Bradley, S., Kirby, E., \& Madriaga, M. (2015). What students value as inspirational and transformative teaching. Innovations in Education and Teaching International, 52(3), 231-242. https://doi.org/10.1080/14703297.2014.880363

Campbell, L. (2019). Teaching in an Inspiring Learning Space: an investigation of the extent to which one school's innovative learning environment has impacted on teachers' pedagogy and practice. Research Papers in Education, OO(00), 1-20. https://doi.org/10.1080/02671522.2019.1568526

Harmin, M. (2006). Inspiring Active Learning. ASCD (2nd ed., Vol. 42). Virginia: ASCD. https://doi.org/10.1109/TGRS.2004.834800

Jensen, K., Adams, J., \& Strickland, K. (2014). Inspirational Teaching: Beyond Excellence and Towards Collaboration for Learning with Sustained Impact. Journal of Perspectives in Applied Academic Practice, 2(2), 37-41. https://doi.org/http://dx.doi.org/10.14297/jpaap.v2i2.88

Lamb, M., \& Wedell, M. (2013). Inspiring English Teachers: a Comparative Study of Learners Perceptions of Ispirational Teaching. ELT Research Paper, 13(13-03).

Lubicz-Nawrocka, T., \& Bunting, K. (2019). Student perceptions of teaching excellence: an analysis of student-led teaching award nomination data. Teaching in Higher Education, 24(1), 63-80. https://doi.org/10.1080/13562517.2018.1461620

Tuğrul Mart, Ç. (2013). A Passionate Teacher: Teacher Commitment and Dedication to Student Learning. International Journal of Academic Research in Progressive Education and Development, 2(1), 2226-6348.

Williams, L., Nixon, S., Hennessy, C., Mahon, E., \& Adams, G. (2016). Inspiring to inspire: Developing teaching in higher education. Cogent Education, 3(1), 1-12. https://doi.org/10.1080/2331186X.2016.1154259 